\title{
FURTHER EXPERIENCES OF INTRA-OCULAR ACRYLIC LENS SURGERY* WITH A REPORT OF MORE THAN 100 CASES \\ BY
}

\author{
HAROLD RIDLEY
}

London

THE intra-ocular acrylic lens operation has now been practised for $3 \frac{1}{2}$ years, but it was not until March 1, 1951, that a satisfactory lens was employed. Since then over 150 operations have been performed (Table 1). The experience gained from a considerable series of cases under the care of one surgeon may now be of value, for though the lens design and general technique have not been changed many lessons have been learned.

TABLE I

SCHEDULE OF 140 CASES

\begin{tabular}{c|c|c|c}
\hline Series No. & Date & No. of Cases & Remarks \\
\hline $1^{*}$ & $1949-50$ & 4 & $\begin{array}{c}\text { These extracapsular cases are omitted as } \\
\text { lenses were of abnormal specification }\end{array}$ \\
\hline $2^{*}$ & $1950-51$ & $\begin{array}{r}21 \text { extracapsular } \\
2 \text { intracapsular }\end{array}$ & \\
\hline 3 & $1952-53$ & $\begin{array}{c}70 \text { extracapsular } \\
16 \text { intracapsular }\end{array}$ & $\begin{array}{c}5 \text { extracapsular cases operated on in } \\
\text { U.S.A. and Canada omitted. }\end{array}$ \\
\hline 4 & 1953 & 29 extracapsular & Results not yet assessed. \\
\hline
\end{tabular}

*B.J.O. (1952), 36, 121.

\section{Toleration of the Intra-Ocular Acrylic Lens}

The first and most important observation is that the artificial lens of standard design composed of Transpex and correctly inserted in an eye is well tolerated for several years. We do not, of course, yet know whether any degenerative changes will be found to occur either in the patient's eye or in the acrylic lens in 10 years or in 50 years, but at the present time there is nothing to suggest future trouble. On the contrary, the longer the lens has been in place the better it appears to be tolerated, the clearer is its surface, and the whiter the eye. This is of overwhelming importance, for had the contrary been found it might have been necessary to discard the operation or at least modify the lens or the surgical technique. 
Surgical Technique

This has undergone little change since the operation was first described. The pre-operative pupil size is important and not always easy to adjust. No drops other than cocaine and adrenaline are now used, and about $\frac{2}{3}$ dilatation $(6 \mathrm{~mm}$.) is desirable. Without homatropine considerable tone is left in the iris and the effect of miotics, when necessary, is rapid. If the aperture is too large it is difficult to place the lens edge beneath the lower part of the iris, and delay may be caused during the operation while miotics constrict the pupil, for clearly the section cannot be closed and the operation concluded until the lens is securely in place behind the iris. Frequently, during extraction of the cataract or irrigation of the anterior chamber, the pupil will constrict, but the acrylic lens can be made to slide through a pupil as small as $3 \mathrm{~mm}$.

Efficient removal of the anterior capsule before expression of the lens is also important, but may prove far from easy. Probably the best technique is to incise the capsule with a cystitome around the lower half of the pupil, and then to grasp the central area with capsule forceps, tearing away as large a piece as possible. Sometimes it may be necessary to insert the forceps more than once. After expression of the nucleus, thorough irrigation of the anterior chamber with sterile normal saline is essential for adequate removal of soft lens matter. This can be surprisingly effective, and it has been found possible to obtain satisfactory results with very immature cataracts, even with those confined to the posterior cortex in which intracapsular technique would formerly have been employed. It is remarkable that throughout the series it has never yet been found necessary to postpone insertion of the acrylic lens until a second operation. Two-stage surgery has, however, been performed where a lens has previously been removed by perfect extracapsular surgery or as a result of trauma, and it would certainly be advisable if soft matter remained in the eye.

If after irrigation some anterior capsular remnants are seen in the upper part of the eye, they are best removed by seizing them with smooth bladed capsule forceps and cutting with de Wecker's scissors, not tearing them away for fear of removing the posterior capsule as well, so rendering the operation an "inadvertent intracapsular ". If capsule tags remain in the lower part of the eye, it may not be possible to reach them for treatment in this way, but the lens can be slid beneath them and the remnants left to shrink up. A final irrigation after the corneo-scleral sutures are tied helps to centralize the lens and permits the pupil to move freely over it from the beginning.

Vitreous loss has occurred in only three of 140 cases in which an intra-ocular acrylic lens has been used. In one, an early deliberate intracapsular, the lens broke the vitreous face and had to be removed immediately. In one, a traumatic cataract, vitreous prolapsed through a hole in the centre of the posterior capsule; the lens was inserted and, though the eye looks satisfactory, acuity is only $6 / 60$, which suggests further intra-ocular traumatic disturbance. In one case a small bead of vitreous came through the peripheral iridectomy, but the case has done well. It must be admitted that in a few more cases vitreous has been lost during the extraction but as the acrylic lens has not been employed in these operations the accident cannot be attributed to the lens. In some at least of these it is highly probable that pre-operative subluxation of the lens was present, for with monocular cataracts of obscure aetiology this and other complications must inevitably be encountered occasionally. 


\section{Lens Design}

The lens design appears to have been fortunate and no change has been made. The precise position within the eye clearly affects the final refraction, but usually the eye is rendered about $1 \mathrm{D}$ myopic compared with its fellow, which, with a fixed focus, is preferable to emmetropia should the unoperated eye be normal. The present diameter of $8.35 \mathrm{~mm}$. appears satisfactory as regards ease of insertion, adequate retention in place, and absence of pressure on the ciliary region and filtration angle.

\section{Intracapsular Cases}

The combination of intracapsular extraction and insertion of an acrylic lens proved unsatisfactory. Deliberate intracapsular technique was employed in ten cases in which the cataract, though causing gross visual disturbance, was largely confined to the nucleus or the posterior cortex. It proved possible to slide the acrylic lens over the unbroken vitreous face and to set it in position behind a central and circular pupil, a procedure which clearly requires exceptional care and must carry far more than average risk.

In eight other cases, described as " inadvertent intracapsulars", extracapsular extraction had been planned but the posterior capsule was removed accidentally. Sometimes, after extraction of the lens, tags of anterior capsule are seen and, if these are seized with forceps and pulled out, the thin posterior capsule or a large portion of it is apt to be removed too.

Ten eyes underwent deliberate intracapsular extraction. In all these the intraocular acrylic lens was inserted perfectly, but in no less than seven it underwent spontaneous and generally gradual dislocation into the base of the vitreous chamber. This misfortune occurred not immediately, but several months after operation, in some instances in association with attacks of coughing. Since only three cases remain satisfactory, the incidence of late dislocation is prohibitive, and the intracapsular technique must be regarded as contraindicated.

Eight eyes are known to have had "inadvertent intracapsular extraction", and there may be others in which damage to the posterior capsule has occurred unobserved. In three of these cases dislocation resulted, in one only 8 days after operation just when the patient was due to return home.

It is interesting however to note that, unlike a dislocated natural lens, the acrylic lens sets up little if any reaction in the eye, especially if the vitreous face is unbroken; this observation has been confirmed by other surgeons. The patients, however, though they may have good acuity with an aphakic spectacle correction, are bitterly disappointed by the change, and this emphasizes the optical advantages of the intraocular acrylic lens.

It is evident that without an intact posterior lens capsule the risk of late dislocation of the intra-ocular acrylic lens is inacceptable. This finding was not unexpected, but it is unfortunate, because intracapsular surgery is followed by very slight reaction and the eye may have an active pupil and good sight as early as the first post-operative dressing. 
TABLE II

VISUAL RESULTS (INTRACAPSULAR)

\begin{tabular}{|c|c|c|c|c|c|c|c|c|c|c|}
\hline $\begin{array}{l}\text { Visual } \\
\text { Acuity }\end{array}$ & $\begin{array}{c}6 / 6 \text { to } \\
6 / 5\end{array}$ & $6 / 9$ & $6 / 12$ & $6 / 18$ & $6 / 24$ & $6 / 36$ & $6 / 60$ & $\begin{array}{c}\text { Below } \\
6 / 60\end{array}$ & $\begin{array}{c}\text { Lens } \\
\text { Dislocated }\end{array}$ & $\begin{array}{l}\text { Patient } \\
\text { Dead or } \\
\text { Untraced }\end{array}$ \\
\hline $\begin{array}{c}\text { Deliberate } \\
10\end{array}$ & 1 & 1 & 1 & - & - & - & - & - & 7 & - \\
\hline $\begin{array}{c}\text { Inadvertent } \\
8\end{array}$ & 3 & 1 & 1 & - & - & - & - & - & 3 & - \\
\hline
\end{tabular}

Most of the eyes with dislocated acrylic lenses can see well with an aphakic spectacle lens.

\section{Extracapsular Cases}

Insertion of an intra-ocular acrylic lens after extracapsular extraction is the only method now employed, and with good surgery can produce excellent results.

Where the posterior lens capsule has not been damaged there has been no dislocation of the lens in the absence of trauma. Three cases however had injuries. A boy was struck in the eye by a fist and one half of the lens, which was never quite satisfactorily placed, slipped in front of the iris; reposition was unsatisfactory and the lens had to be removed. A man was struck on the eye by a tennis ball; the displacement was similar but was satisfactorily treated by passing an iris repositor through a small corneal incision. The only other case was that of a woman who fell to the ground and was rendered unconscious for 10 to 15 minutes; her face and brow were cut and the acrylic lens dislocated into the vitreous through a tear in the posterior capsule.

TABLE III

VISUAL RESULTS (EXTRACAPSULAR)

\begin{tabular}{c|c|c|c|c|c|c|c|c|c|c}
\hline $\begin{array}{c}\text { Visual } \\
\text { Acuity }\end{array}$ & $\begin{array}{c}6 / 6 \text { to } \\
6 / 5\end{array}$ & $6 / 9$ & $6 / 12$ & $6 / 18$ & $6 / 24$ & $6 / 36$ & $6 / 60$ & $\begin{array}{c}\text { Below } \\
6 / 60\end{array}$ & $\begin{array}{c}\text { Lens } \\
\text { Dislocated }\end{array}$ & $\begin{array}{c}\text { Patient } \\
\text { Dead or } \\
\text { Untraced }\end{array}$ \\
\hline $\begin{array}{c}\text { Series 2 } \\
21\end{array}$ & 7 & 5 & 0 & 2 & 1 & 1 & & 1 & 1 & 3 \\
\hline $\begin{array}{c}\text { Series 3 } \\
70\end{array}$ & 21 & 20 & $\begin{array}{c}7 \\
1 \text { amblyopic }\end{array}$ & 9 & $\begin{array}{c}2 \\
1 \text { amblyopic }\end{array}$ & 2 & $\begin{array}{c}2 \\
2 \text { amblyopic }\end{array}$ & 5 & 1 & 1 \\
\hline $\begin{array}{c}\text { Total } \\
\text { Percent. }\end{array}$ & 34 & 32 & 8 & 12 & 3 & 4 & - & 7 & - & - \\
\hline
\end{tabular}

Among extracapsular cases, at least four poor visual results were due to amblyopia or lesions of the retina. In the two traumatic dislocations the former acuity was $6 / 9$.

The refraction of the acrylic lens eye resembles that of the other eye in the great majority of cases. (In one, both eyes require $-6.0 \mathrm{D}$.cyl., axis $90^{\circ}$ ). The average post-operative astigmatism is $1.75 \mathrm{D}$.

Among extracapsular cases, nearly two-thirds can see $6 / 9$ or more (without the magnification provided by a catarAmong extracapsular cases, nearly two-thir
act glass) and half of these can see $6 / 6$ or $6 / 5$.

Improvement in acuity is expected in many cases which are at present below standard. Only five eyes, other than those which are amblyopic or contain dislocated lenses, seem beyond reasonable hope of 6/9.

\section{Posterior Capsule}

It was foreseen at the start by many surgeons that the posterior capsule might thicken, and that "secondary cataract" might cause visual deterioration some time after operation. It was hoped, however, that the pressure of the lens on this very thin membrane would prevent wrinkling and thickening and this, in fact, has been our experience so far. Case 2 underwent capsulotomy from behind; this proves 
that this operation can be performed, but in no other patient has it been considered necessary. It is probable that in some cases visual acuity is somewhat reduced by opacities in this membrane, though in many visual acuity of $6 / 6$ or $6 / 5$ has been attained in spite of the presence of an intact posterior capsule.

\section{Complications}

Post-operative Iritis.-Some degree of post-operative iritis is to be expected, though it is slight in intracapsular and two-stage extracapsular operations. This most troublesome common complication is attributable to operative trauma, and perhaps to the leaving of a little cortex adherent to capsular tags. Care must be taken to wash the lens adequately after sterilization and to perform the operation neatly and gently, avoiding any unnecessary manipulation. After operation the pupil should be maintained with atropine at a diameter of about $4.5 \mathrm{~mm}$. Cortisone ointment is valuable in controlling inflammation but should not be used before the fifth day for fear of delaying the healing of the corneo-scleral section. Though individual variation is inevitable, fair vision may be expected in one month and good visual acuity in 3 months.

Occlusion of the Pupil.-In some cases, especially if the pupil has been allowed to constrict, a dense inflammatory membrane may occlude the pupil. When the iritis is no longer active this may be effectively divided by manipulation of a Ziegler's knife passed through the limbus, care being taken to avoid damaging the lens. Mydricaine and cortisone are injected subconjunctivally. The results are often dramatic, 6/12 usually being attained within one week with a good prospect of higher visual acuity later.

Glaucoma.-A slight temporary rise of tension has been encountered in a few cases, but has readily responded to miotics; a drainage operation has been required in one case in which the cataract surgery was very defective. Secondary glaucoma due to iris bombé caused by dense synechiae around the pupil was met with twice but responded to iridotomy. There have also been two cases of a somewhat similar type of secondary glaucoma associated with loss of the anterior chamber. This complication due to seclusion of the pupil by broad adhesions between the surface of the lens and the back of the iris had been treated by performing one or more small peripheral iridotomies.

Post-operative Diplopia.-This has occurred in a few cases in association with prolonged disuse of the cataractous eye. So far it has never failed to disappear spontaneously without muscle surgery or suppression of one image, even though in one case there was pre-operative divergence of $10^{\circ}$.

Constitutional Disease.-Diabetes, and other forms of severe constitutional disorder, such as gross hypertension, cardiac failure, and severe respiratory disease, are regarded as a contraindication to any surgery except that which is essential and simple. Nevertheless intra-ocular acrylic lenses have been inserted in the eyes of three fully controlled diabetics. In two of these more than average iritis resulted but the other was quite uncomplicated and provided a visual acuity of $6 / 6$. Care is required in the selection of cases, and where more than average risk is present this should be explained to the patient. 
Heterochromic Cyclitis.-This frequent cause of uniocular cataract is not a contra-indication to the use of an intra-ocular acrylic lens. No more than average post-operative reaction is usual in these cases.

\section{Removal of Acrylic Lens}

In only one case, following traumatic subluxation, has an acrylic lens been removed. It was readily grasped by the peripheral grooves. So far we have not removed any eye containing an acrylic lens.

\section{Discussion}

The verdict of $3 \frac{1}{2}$ years experience is that the intra-ocular acrylic lens operation; has a definite place in ophthalmic surgery.

For the uniocular cataract it is unrivalled and may well prove to be the ultimate treatment, for binocular vision is restored. Unlike a contact glass, the intraocular acrylic lens causes no unnatural magnification which may prevent binocular vision, nor any sensation of a foreign body; it requires no maintenance or adjustment by the patient and does not give rise to temporary veiling. There are relatively few cataract patients who have the dexterity to insert a contact glass or the perseverance to become accustomed to the discomfort, however accurate the fit.

In senile cataract the advantages are less obvious, for plain extraction gives the patient the two essentials, the ability to go about alone and to read. Often, however, aphakic patients enabled to see $6 / 6$ in the centre of the field complain that " the sight is not natural". Many refuse to wear a cataract glass if the other eye retains fair sight.

In assessing the results, it is not right to judge solely by the central acuity of the single eye; the total visual function of the patient is the true criterion. The intraocular acrylic lens restores throughout the full visual field natural sight which may be quite equal to that of a normal presbyopic eye in which accommodation is lost. Furthermore, with an intra-ocular acrylic lens in one eye, both eyes can be used together until the second cataract matures. Many patients prefer binocular vision with acuity even as low as 6/12 and 6/12 to an incompatible pair of eyes, one seeing 6/12 and the other capable of 6/6 with an aphakic correction which they dislike. Among the most grateful and satisfied patients are those who have 6/18 unaided with one eye, and the ability to read newsprint without a glass with the eye with an acrylic lens.

Time has yet to show whether in cases of bilateral cataract the evident optical, cosmetic, and psychological advantages outweigh the disadvantages of extra complication and slower recovery of sight compared with the classical technique; but there is evidence, in the scores of good results and the general absence of severe complications, that in years to come, though not at present, the acrylic lens may be the operation of choice for all cataracts which are uncomplicated by severe ocular or constitutional disease. There is no indication so far that the lenticulus greatly increases the risk of late complications or that it will not last a lifetime; 
it seems that after full convalescence, though this may sometimes be prolonged, further trouble need not be anticipated. Several patients now have successful intra-ocular acrylic lenses in both eyes.

Perhaps no other operation in ophthalmic surgery more accurately reflects the degree of skill and care of good surgery. The surgeon and his patient are playing for higher stakes. Success will be rewarded by restoration of almost natural vision very different from that provided by cataract glasses. On the other hand, any unnecessary manipulation or surgical faults which might pass with plain extraction are liable to be heavily penalized. The new surgery is not yet advisable for every cataract patient and is as yet only to be recommended to thoroughly experienced surgeons, but reports from many parts of the world are evidence that results can be obtained which are unequalled by any other form of cataract treatment. Now at last nearly normal and natural sight can be restored, sometimes without any external optical aid.

\section{Summary}

The lessons learnt from over one hundred intra-ocular acrylic lens operations are described, and a Table of visual results is appended.

\section{REFERENCES}

Arruga, A. (1951). Arch. Soc. oftal. hisp.-amer., 11, 1490. (1952). Rev. esp. Oto-neuro-oftal., 11, 255.

ARruGA, H. (1952). Bull. Soc. franc. Ophtal., 65, 423. (1953a). Clin. y Lab., 55, 17. (1953b). Personal communication.

Bain, W. E. S. (1952). Proc. roy. Soc. Med., 45, 29.

Cavara, V., and Ciotola, G. (1953). Boll. Oculist. Paris, 32, 129.

Miller, H. A. (1953). Ann. Oculist. (Paris), 186, 312.

Perritr, R. (1952). Personal communication.

REECE, W. (1953). J. Amer. med. Ass. In the press.

RIDLEY, H. (1951a). Trans. ophthal. Soc. U.K., 71, 617. (1951b). St Thom. Hosp., Rep., Second ser., 7, 12. (1952a). Lancet, 1, 118.

(1952b). British Journal of Ophthalmology, 36, 113.

(1952c). J. int. Coll. Surg., 18, 825.

(1953). Trans. Amer. Acad. Ophthal. Otolaryng., 57, 98.

VANRelL, F. A., and Diaz, P. C. T. R. (1953). Dia méd. urug., 20, 235. 